\title{
Diagnostic challenge: chronic bullous dermatosis of childhood
}

\author{
Pasupathy U. ${ }^{1 *}$, Bhaskar N. ${ }^{2}$, Raghunathan J. ${ }^{3}$, Chidambaram . $^{4}$ \\ DOI: https://doi.org/10.17511/ijpr.2020.i04.05 \\ 1* Umapathy Pasupathy, Professor, Department of Pediatrics, Sri Ramachandra Institute of Higher Education and Research, Chennai, Tamil \\ Nadu, India. \\ 2 Nithya Bhaskar, Junior Resident, Department of Pediatrics, Sri Ramachandra Institute of Higher Education and Research, Chennai, Tamil \\ Nadu, India. \\ 3 Janani Raghunathan, Junior Resident, Department of Pediatrics, Sri Ramachandra Institute of Higher Education and Research, Chennai, \\ Tamil Nadu, India. \\ 4 Sathya Chidambaram, Junior Resident, Department of Pediatrics, Sri Ramachandra Institute of Higher Education and Research, Chennai, \\ Tamil Nadu, India.
}

Chronic bullous dermatosis of childhood is a rare acquired autoimmune disease characterized by subepidermal blistering disease of childhood with linear deposition of IGA on immunofluorescence. A 3-year-old female child presented with lesions mimicking Hand foot mouth disease which gradually progressed to isolated multiple bullous pruritic lesions all over the body. The absence of a characteristic string of pearl appearance, the histopathological findings, and the response to immunosuppressants lead us to the diagnosis of pox like lesions. Histopathology revealed parakeratosis with increased eosinophils. The child finally responded to a combination of cyclosporine and steroids. Although CBDC is common in lower trunk and genitalia it can also present as generalized bullous lesions. Here the current study reports a case of chronic bullous dermatosis of childhood that presented as a diagnostic challenge.

Keywords: Chronic bullous dermatosis, Diagnostic challenge, Generalized bullae, Autoimmune Disease, IGA deposition, Parakeratosis

Corresponding Author

Umapathy Pasupathy, Professor, Department of Pediatrics, Sri Ramachandra Institute of Higher Education and Research, Chennai, Tamil Nadu, India. Email: drumapathy07@gmail.com

\section{How to Cite this Article}

To Browse

Pasupathy U, Bhaskar N, Raghunathan J, Chidambaram S. Diagnostic challenge: chronic bullous dermatosis of childhood. Pediatric Rev Int J Pediatr Res. 2020;7(4):190-193.

Available From

https://pediatrics.medresearch.in/index.php/ijpr/arti cle/view/584

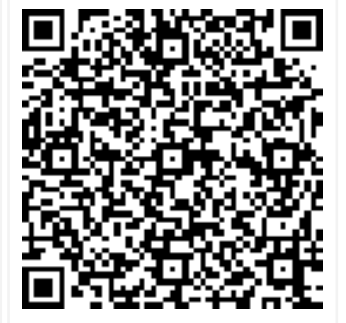

Manuscript Received 2020-02-06

Conflict of Interest No

Review Round 1
2020-02-17
Funding
Nil

(ㄷ) 2020 by Umapathy Pasupathy, Nithya Bhaskar, Janani Raghunathan, Sathya Chidambaram and Published by Siddharth Health Research and Social Welfare Society. This is an Open Access article licensed under a Creative Commons Attribution 4.0 International License https://creativecommons.org/licenses/by/4.0/ unported [CC BY 4.0].

\begin{tabular}{|c|c|}
\hline $\begin{array}{c}\text { Review Round } 2 \\
2020-02-22\end{array}$ & Review Round 3 \\
\hline $\begin{array}{c}\text { Ethical Approval } \\
\text { Yes }\end{array}$ & $\begin{array}{c}\text { Plagiarism X-checker } \\
9 \%\end{array}$ \\
\hline
\end{tabular}

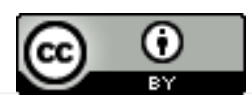




\section{Introduction}

Chronic Bullous Dermatosis of childhood is the most common, non- hereditary autoimmune blistering disorder of childhood. It is characterized by the presence of continuous linear deposits of IgA autoantibodies along the basement membrane zone [1]. In this case report, the key features of this rare Autoimmune Bullous Disease are revisited.

Diagnosis of Chronic bullous dermatosis requires 3 criteria, that is a vesicular or a bullous eruption involving the skin or mucous membrane, A subepidermal neutrophilic predominate infiltration on histology and basement membrane deposition of IgA on a linear manner [2].

The antigens involved in this are LAD-1 and LABD97, which represent the extracellular collagen of XV11 [3].The pathogenesis involves both cell and humoral mediated immunity, production of IgA antibodies against the antigens and the linear pattern of deposition determines the humoral response [4]. The cellular response is by complement activation and by the release of proteolytic enzymes [5].

CBDC commonly affects the preschool group of children, although a few cases of neonatal CBDC has been reported $[1,3]$.

It usually presents as tense polymorphic blisters, with the newer lesions forming annular rings around the older lesions with peripheral blisters known as the "string of pearls" sign [6]. These lesions are usually pruritic or non-pruritic arising from normal or erythematous skin base [1]. Predominant location includes the lower extremities and genital region with occasional involvement over the face and upper extremities [3].

Differential diagnosis includes bullous impetigo, dermatitis herpetiformis, bullous pemphigoid, erythema multiforme [1]. Lesional skin histology reveals a neutrophilic predominant subepidermal cavity [3]. Direct immunofluorescence shows linear IgA deposition, literature has also shown deposition of IgG, IgM, C3 $[7,8]$.

Commonly used therapy includes dapsone and sulfapyridine, which helps to achieve long-lasting remission [9].Dapsone combined with steroids that can be used as monotherapy in generalized CBDC [10]. Other immunosuppressive agents used are cyclosporine, methotrexate, and cyclophosphamide [2].

\section{Case Report}

A 3year developmentally normal child developed few itchy skin lesions in less than two weeks duration. The lesions gradually progressed in few days to blisters which increased in number and size over 2 days (Figure 1 ).

The lesion initially started around the arms and legs and later involved the extremities, trunk, and genitals (Figure 2).

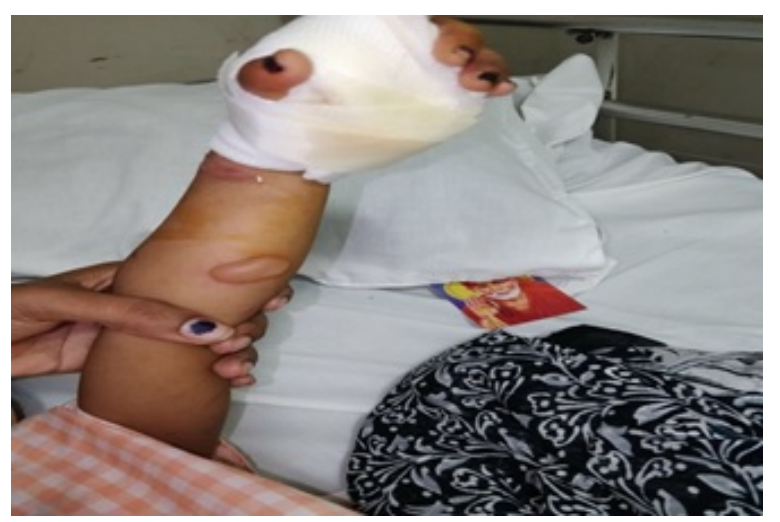

Fig-1: Presence of vesicular blister-like lesion over the forearm.

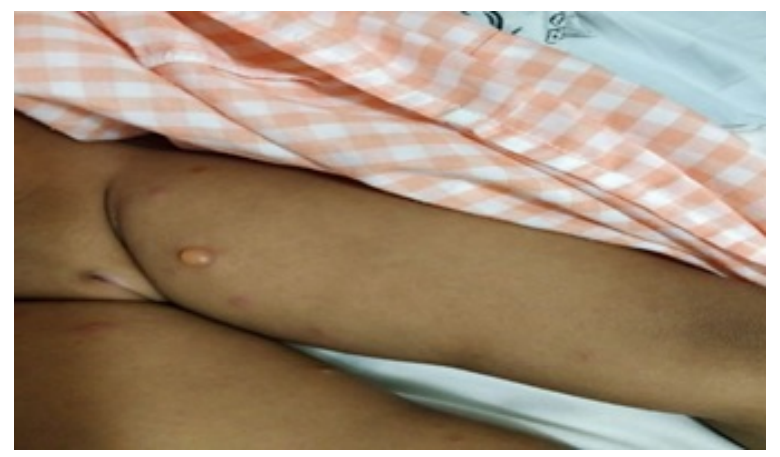

Fig-2: Vesicular bullous lesions over the inner thigh.

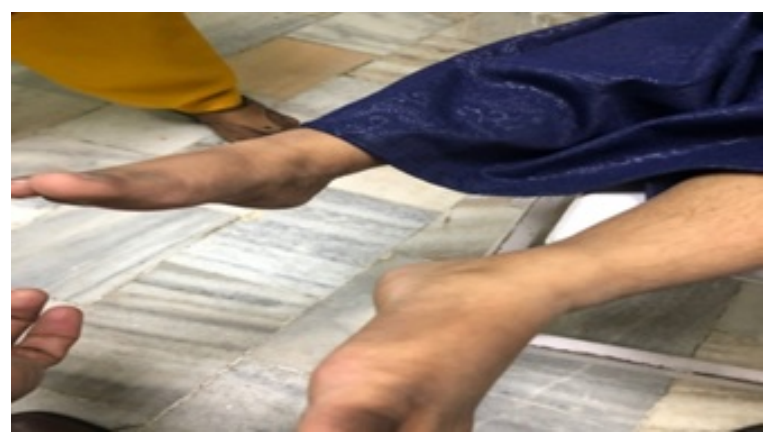

Fig-3: Completely resolved skin lesions. 


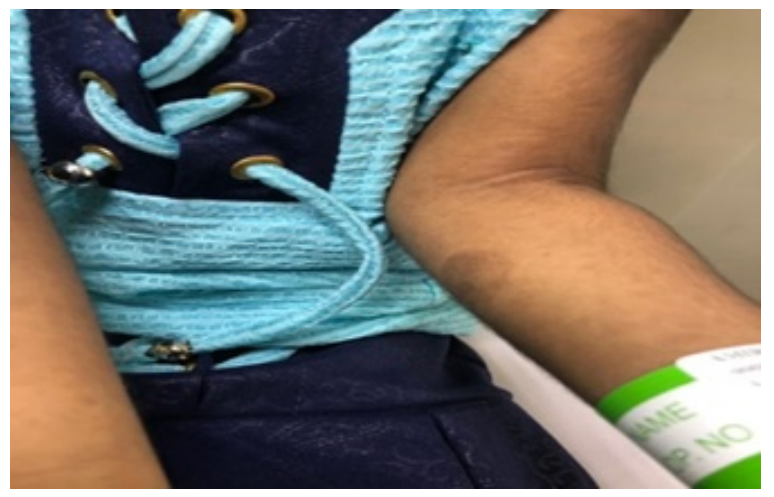

Fig-4: Completely resolved lesions over the forearm.

The largest among them was seen on the palms. Serosanguinous foul-smelling discharge was associated with the lesion. There was pronounced itching. A characteristic string of pearl appearance was not seen, only isolated lesions were noted. Tense bullae with the erythematous base were present asymmetrically. On examination, the Nikolsky sign was absent. The mucous membrane, hair, and nails were spared.

There was no family history of the cutaneous disease and a history of any drug intake or any history of upper respiratory tract infection. No history of trauma, exposure at the site of blisters.

Investigations revealed normal counts with poly predominance with mild eosinophilia. The erythrocyte segmentation rate was elevated. The coagulation profile and the International normalized ratio were within normal limits. CRP was elevated (2.4). Direct smear - gram stain from the left leg showed an abscess with occasional pus cells, occasional epithelial cells, and no organisms. Pus culture and blood culture were sterile.

Histopathological examination revealed linear fragments of tissue shown of parakeratosis with overlying hyperkeratosis. It also revealed many eosinophils are scattered with few micro abscesses within the parakeratotic column. Thus, the roof of the bulla showed increased eosinophils in the parakeratotic layer.

The child was initially started with IV antibiotics with the suspicion of infected bullae. The child had received IV cloxacillin and IV vancomycin for 3 days. The child received IV hydrocortisone $(1 \mathrm{mg} / \mathrm{kg} / \mathrm{dose}$ ) with IV acyclovir. Derooting of the bullae was done with biopsy and silver arginate dressing was applied. The lesions were was refractory.
Other tests including LFT, RFT, and urine analysis were within normal limits. The child was started on oral cyclosporine $(0.25 \mathrm{mg} / \mathrm{kg} /$ dose $)$ along with oral steroids. Antibiotics and oral antivirals were continued for 7 days. The child had a mild elevation of hepatic parameters which normalized in course of time. The child had recovered, lesions completely resolved within two weeks of starting treatment with no recurrence as of now (Figure 3 and Figure $4)$. Due to denial from parents and early resolution of lesions immunofluorescence could not be done.

\section{Discussion}

Chronic Bullous Dermatosis of Childhood is characterized by homogenous linear deposits of IGA at the epidermal basement membrane. Onset in children is usually before five years of age and remits by six to eight years of life [1].Though both histological and immunofluorescence studies are of utmost importance in diagnosis, in developing countries the diagnosis is mainly clinical with histopathological evidence. Humoral and cellular responses contribute to the pathogenic mechanism contributing to the blister formation. Chronic Bullous Dermatosis of Childhood is characterized by clinical polymorphism with a "string of pearls" or cluster of jewels appearance being the most typical presentation [3].

In our case, the rapidly progressing lesion leads to a suspicion of pox. The characteristic string of pearl appearance was absent. Initially, the Hand Foot Mouth variant was considered following which infected bullae were considered leading to challenges. Thus, the current study emphasizes in the case report, rapidity in progression with absence classical cluster of pearls and rapid resolution of lesions within weeks and complete recovery with cyclosporine.

\section{Reference}

01. Thappa DM, Jeevankumar B. Chronic bullous dermatosis of childhood Postgrad. Med $\mathrm{J}$. 2003;79(934)437.

doi: $10.1136 /$ pmj.79.934.437 [Crossref]

02. Farley-Li J, Mancini AJ. Treatment of Linear IgA Bullous Dermatosis of Childhood with Mycophenolate Mofetil. Arch Dermatol. 2003;139(9)1121-1124.

doi: $\quad 10.1001 /$ archderm.139.9.1121 [Crossref] 
03. Patsatsi A. Chronic bullous disease or linear IgA dermatosis of childhood-revisited. J Genet Syndr Gene Ther. 2013;4(6)151.

doi: $\quad 10.4172 / 2157-7412.1000151 \quad$ [Crossref]

04. Lin MS, Fu CL, Olague-Marchan M, Hacker MK, Zillikens D, Giudice GJ, et al. Autoimmune responses in patients with linear IgA bullous dermatosis- both autoantibodies and $T$ lymphocytes recognize the NC16A domain of the BP180 molecule. Clin Immunol. 2002;102(3)310-319.

doi: $10.1006 /$ clim.2001.5177 [Crossref]

05. Caproni M, Rolfo S, Bernacchi E, Bianchi B, Brazzini B, Fabbri P. The role of lymphocytes, granulocytes, mast cells and their related cytokines in lesional skin of linear IgA bullous dermatosis. Br J Dermatol. 1999;140(6)10721078.

doi: $10.1046 /$ j.1365-2133.1999.02904.x [Crossref]

06. Tate C, Christian W, Newell L. Chronic Bullous Dermatosis of Childhood and the String of Pearls Sign. J Pediatr. 2018;202;325.

doi: $\quad 10.1016 /$ j.jpeds.2018.07.070 [Crossref]
07. Petersen MJ, Gammon WR, Briggaman RA. A case of linear IgA disease presenting initially with IgG immune deposits. J Am Acad Dermatol. $1986 ; 14(6) 1014-1019$.

doi: $10.1016 / \mathrm{s} 0190-9622(86) 70125-4 \quad$ [Crossref]

08. Powell J, Kirtschig G, Allen J, Dean D, Wojnarowska F. Mixed immunobullous disease of childhood- a good response to antimicrobials. $\mathrm{Br}$ J Dermatol. 2001;144(4)769-774.

doi: $10.1046 / j .1365-2133.2001 .04131 . x$ [Crossref]

09. Fortuna G, Marinkovich MP. Linear immunoglobulin A bullous dermatosis. Clin Dermatol. 2012;30(1)38-50.

doi: 10.1016/j.clindermatol.2011.03.008 [Crossref]

10. Monia K, Aida K, Amel K, Ines Z, Becima $F$, Ridha KM. Linear IgA bullous dermatosis in tunisian children- 31 cases. Ind J Dermatol. 2011;56(2)153-159.

doi: 10.4103/0019-5154.80406 [Crossref] 